\title{
Predictions on the Internal Loads and Structural Deflection in a Full-scale Experimental Bearingless Rotor
}

\author{
WongJong Eun* and HanYeol Ryu* \\ Department of Aerospace Engineering, Seoul National University, Seoul 151-744, Korea
}

\author{
SangJoon Shin** \\ Department of Aerospace Engineering, Institute of Advanced Aerospace Technology, Seoul National University, Seoul 151-744, \\ Korea
}

\section{YoungJung Kee*** and Deog-Kwan Kim***}

Korea Aerospace Research Institute, Daejeon 305-806, Korea

\begin{abstract}
In this paper, the unsteady aerodynamics and blade structural dynamics of an experimental bearingless rotor were analyzed. Due to the multiple load path and nonlinear behavior of a bearingless rotor, sophisticated structural modeling and structuralaerodynamic coupled analysis is required. To predict the internal load and deformation of an experimental bearingless rotor, trim analysis was implemented. The results showed good agreement when compared with those predicted by CAMRAD II the rotorcraft comprehensive analysis. It is possible to extend the present structural-aerodynamic combined analysis to further advanced configurations of the bearingless rotor in the future.
\end{abstract}

Key words: Bearingless Rotor, Aeromechanical Analysis, Rotorcraft Comprehensive Analysisi

\section{Introduction}

In order to design a bearingless rotor, the capability to predict internal loads and structural deflection accurately is crucial. The precise prediction of these quantities guarantees safety of a bearingless rotor design. The prediction of large elastic deflections at its inboard will also be important. A snubber, which is located between the flexbeam and torque tube, influences the imaginary hinge position. To achieve a benign prediction, accurate aerodynamic-structural coupled analysis is required. Also, an analysis that considers the detailed components such as snubber and pitch link, is required.

In previous studies, there have been various attempts to analyze bearingless rotors. Hodges [1] performed stability analysis for a bearingless rotor using FLAIR, based on the moderate deflection beam formulation. His results regarding the damping coefficient showed a good correlation with the measurements obtained from the small-scale rotor test $[2,3]$. Lim and Lee [4] analyzed the aeroelastic characteristics of a bearingless rotor. They used large deflection beam theory which relies upon a simplified assumption on the cross sectional analysis. They predicted the damping coefficient, which showed good agreement with measurements. The aeroelastic response was also obtained by a time-marching solution procedure under the small perturbation assumption. However, the internal loads and structural deflection were not estimated. Staruk, et al. [5] suggested three-dimensional structural models for the multiple flexible bodies. Three rotor types were created: a bearingless rotor, an articulated rotor, and a teetering rotor. Static and dynamic analyses for those rotors were performed. However, the aeromechanical
This is an Open Access article distributed under the terms of the Creative Commons Attribution Non-Commercial License (http://creativecommons.org/licenses/by$\mathrm{nc} / 3.0 /$ ) which permits unrestricted non-commercial use, distribution, and reproduction in any medium, provided the original work is properly cited. (c) * Graduate Student

** Professor, Corresponding author: ssjoon@snu.ac.kr *** Senior Researcher, Principle Researcher 
response of a rotating blade in atmosphere was not obtained. Anathan and Bearder [6] conducted a CFD-CSD coupled analysis on an MDART bearingless rotor [7,8] and its internal loads were obtained. Prediction of the internals load near the blade tip showed good correlation with measurements. However, verification of the structural deflection was not performed.

Recently, an accurate formulation considering geometrical nonlinearities was adopted for bearingless rotor analysis. CAMRAD II [9] is a rotorcraft comprehensive analysis program, utilizing the displacement-based, geometricallyexact beam formulation. CAMRAD II provides a multibody configuration that is constrained within the average displacement or rotation of the elements at the connecting point [10]. In a more detail, the blade and flexbeam are connected by the structural dynamic interface which is defined half-way between the two ends, with axes aligned with the blade root frame. Connecting axes are defined at the interface point, and then the constraint equation requires that the connecting axes on the two sides (the blade and flexbeam) of the interface should have the same origin and orientation [11]. Regarding the aerodynamics-structural coupled analysis, CAMRAD II is capable of predicting various physical quantities for a bearingless rotor. However, because it uses a displacement-based formulation, additional postprocessing will be required to obtain the internal loads. Its structural modeling capability is restricted to only a few pre-selected simple configurations of the bearingless rotor. Sotoudeh and Hodges [12, 13] introduced fully intrinsic equations, which satisfied the geometrical nonlinearities without displacement or rotation variables, for a bearingless rotor. They analyzed the internal loads for a simplified bearingless rotor and the results showed good agreement when compared with those predicted by DYMORE. However, they used an imaginary, simple bearingless rotor, which has uniform material properties along its span. Also, fully intrinsic equations, which were a force-based formulation, required additional post-processing to obtain the structural deflections and rotations.

Chun, et al. [14], introduced aerodynamic-structural analysis based on the mixed variational geometricallyexact beam formulation and the finite-state dynamic inflow aerodynamics. The advantage of the mixed variational formulation is that displacements, rotations, internal forces, moments, linear/angular momenta are extracted directly. They analyzed the internal loads and structural deflection in a bearingless rotor. Their structural model showed good agreement with DYMORE, and the relevant aerodynamic-structural analysis was verified by comparison with CAMRAD II. They adopted a Lagrange multiplier for multi-body analysis. However, the model uses excessive inflow values which came from the summation of an initial inflow term of the uniform inflow model and the converged inflow values. In this way, discrepancies were induced in the aerodynamic prediction, compared with those predicted by CAMRAD II. Also, a snubber was located on the first beam element of the inboard. It was not possible at that time to locate such a snubber in an arbitrary location. They used experimental bearingless rotor to validate their analysis. But comparisons between analysis and measurement were not included.

In this paper, comparisons of the internal loads and structural deflection between analysis and measurement for a full-scale experimental bearingless rotor is attempted. Especially, the aerodynamic-structural analysis constructed in Ref. 14 will be further improved. The aerodynamic module will be refined to consider accurate inflow quantities. The structural model will be improved including an arbitrary snubber location. To validate such further improvements, a full-scale experimental bearingless rotor, which was developed and whirl-tested by the Korea Aerospace Research Institute [15] will be used. Trim analysis will be conducted both for hover and forward flight conditions. Its prediction results regarding the internal loads and structural deflection will be compared with other predictions. Also, further improvement to the aerodynamic-structural analysis will be attempted for a full-scale experimental bearingless rotor. By adopting the present improved analytical procedure, prediction on the internal loads and structural deflection will be enabled. Its result will be used for verification of the design safety and accurate behavior prediction of a bearingless rotor. Finally, such improved aerodynamicstructural coupled analysis will be applicable to other vehicle structures such as launch vehicles with a multi load path and high aspect ratio wing.

\section{Extensions from the Previously Suggested Analytical Model}

Chun, et al. [14] developed aerodynamic-structural analysis applicable to a bearingless rotor. However, there were few areas that required further improvement. The present analytical model is obtained by extending the aerodynamic-structural analysis developed in Ref. 14. The four important improvements that were added are as follows.

- Multi-body structural model considering kinematic constraints and boundary conditions

A multi-body structural model considering kinematic constraints had already been developed in Ref. 14. However, 
the practical boundary condition of each component, such as the free torque tube root and clamped flexbeam root, were not considered. The multi-body connected structural model was constrained considering both kinematic constraints and the practical boundary condition of each beam element. The present beam model identifies the specific parameters related to each boundary condition.

- Arbitrary snubber location

In Ref. 14, the snubber was located near the first inboard beam element. Thus, it could not predict the inboard blade deflection since the distance between the snubber and the hub was considerable. In this paper, the capability to consider an arbitrary snubber location was incorporated.

- Implementation of the pitch control system

The rotor pitch control components were not included in the structural model in Ref. 14. In this paper, the pitch link was modeled as a combination of an elastic linear spring and a linear viscous damper. Thus, the present structural analysis included the pitch control system to consider a realistic configuration of the rotor system.

- Accurate airload estimation by using the precise inflow quantity

The aerodynamic model included in Ref. 14 provided an incorrect inflow quantity. The incorrect value was added to the inflow quantity, and it induced an inaccurate thrust prediction. In this paper, the estimation of the inflow value was improved

\subsection{Multi-component connection}

A rotor blade, a torque tube, and flexbeams were modeled as one-dimensional beam elements. An example of the bearingless rotor is shown in Fig. 1. At the clevis location,

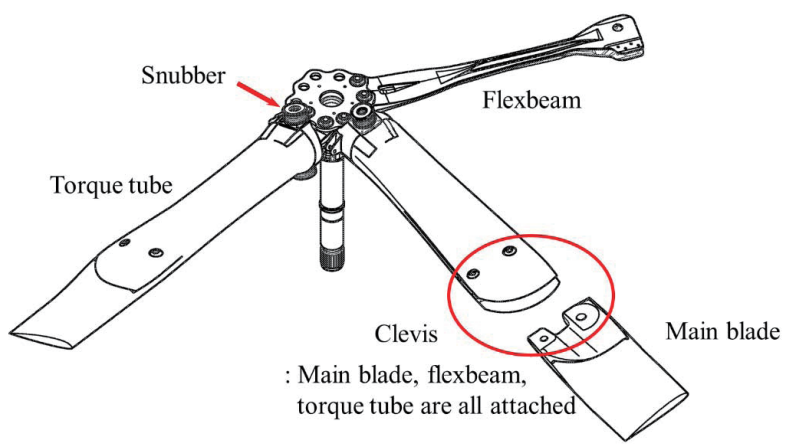

Fig. 1. Example of the bearingless rotor these components were attached in a complicated fashion. The multi-body dynamic analysis was introduced in order to satisfy interconnecting kinematic relationships among those components. The one-dimensional beam model and kinematic relationships are derived in Ref. 14.

Chun, et al. [14] used a nonlinear intrinsic beam formulation originally suggested by Hodges [17]. In that structural model, the kinematic constraints were established at the clevis location for multi-body modeling. The total energy of the multi-body system, which consists of multiple beam elements, was obtained by assembling the energy equations for each beam, as follows.

$$
\Pi=\Pi_{m b}+\Pi_{t t}+\Pi_{f b}
$$

Through the mixed variational formulation, the discretized governing equation of each beam was obtained with $18 \mathrm{~N}+12$ degrees of freedom, including the displacements and rotations, internal forces and moments, as well as the linear and angular momenta. The present geometrically exact beam formulation was expressed in terms of the displacement, rotation, internal forces and moments, linear and angular momenta. Thus, important mechanical quantities, such as internal forces and moments, can be obtained directly from the beam formulation. Equation (2) shows the unknown vector for each beam formulation.

$$
X=\left\{\hat{\Lambda}_{1} \hat{\Lambda}_{1} u_{1}^{T} \theta_{1}^{T} F_{1}^{T} M_{1}^{T} P_{1}^{T} H_{1}^{T} \cdots u_{N}^{T} \theta_{N}^{T} F_{N}^{T} M_{N}^{T} P_{N}^{T} H_{N}^{T} \hat{\Lambda}_{N} \hat{\Lambda}_{N}\right\}^{T}
$$

The hatted terms in Eq. (2) correspond to the unknowns related to boundary conditions. In this paper, the main blade and torque tube were modeled as free-free beams. The flexbeam was modeled as a clamped-free beam. The unknown vectors related to boundary conditions are summarized in Table 1.

At the clevis location, the assumption of cantilevered adjacent components was used. Hence, each component would exhibit the same rotation angle as that of the clevis [14]. To enforce the kinematic constraints among the components in the present structural model, Lagrange multipliers were used as shown in Fig. 2. The energy equations for the clevis constraint were expressed as follows.

$C_{t t}(u, \theta)=C_{f b}(u, \theta)=0$

The constraint energy equations were modeled in

Table 1. Unknowns for the boundary conditions

\begin{tabular}{ccc}
\hline & Clamped & Free \\
\hline Boundary condition & $u_{0}, \theta_{0}=0$ & $F_{0}, M_{0}=0$ \\
Boundary unknowns & $X=\left\{F_{0} M_{0} u_{1} \theta_{1} F_{1} M_{1} P_{1} H_{1} \ldots\right\}$ & $X=\left\{u_{0} \theta_{0} u_{1} \theta_{1} F_{1} M_{1} P_{1} H_{1} \ldots\right\}$ \\
\hline
\end{tabular}


accordance with the total energy equation, Eq. (1). Therefore, the revised total energy equation and its variational form were obtained as follows.

$$
\begin{aligned}
& \Pi=\Pi_{m b}+\Pi_{t t}+\Pi_{f b}+\lambda_{t t} C_{t t}+\lambda_{f b} C_{f b} \\
& \partial \Pi=\partial \Pi_{m b}+\partial \Pi_{t t}+\partial \Pi_{f b}+\sum \lambda_{i} \partial C_{i}+\sum C_{i} \partial \lambda_{i}=0
\end{aligned}
$$

Equation (5) can be expressed as a simple form in Eq. (6).

$$
F_{S}(X)-F_{L}=0
$$

where $F_{S}$ is the structural operator, and $F_{L}$ is the external loads operator. $X$ is the total unknown structural state variable which is as follows.

$$
X_{\text {total }}=\left\{X_{m b} X_{t t} X_{f b} X_{m b-t t} X_{m b-f b}\right\}^{T}
$$

where $X_{m b-t t}$ and $X_{m b-f b}$ are the unknown variables in the constraint equation between the main blade-torque tube and main blade-flexbeam. The Newton-Raphson method was employed to solve the nonlinear equation, Eq. (6). In this procedure, Jacobi matrices were required. The complete Jacobi matrix consists of elemental matrices. The structural operator in Eq. (6) is divided into elemental structural operator, as shown in Eq. (8).

$$
F_{S}(X)=\left\{F_{S_{m b}} F_{S_{u t}} F_{S_{j b}} F_{S_{m b-u}} F_{S_{m b-j b}}\right\}
$$

Thus, the complete Jacobi matrix is derived in Eq. (9).

$$
J=\frac{\partial F_{S}}{\partial X_{\text {total }}}=\left[\begin{array}{cccc}
\frac{\partial F_{S_{m b}}}{\partial X_{m b}} & & \frac{\partial F_{S_{m b-t}}}{\partial X_{m b}} & \frac{\partial F_{S_{m b-f b}}}{\partial X_{m b}} \\
& \frac{\partial F_{S_{t}}}{\partial X_{t t}} & \frac{\partial F_{S_{m b-t}}}{\partial X_{t t}} & \\
\frac{\partial F_{S_{m b}}}{\partial X_{m b-t t}} & \frac{\partial F_{S_{t t}}}{\partial X_{m b-t t}} & \frac{\partial F_{S_{m b-f b}}}{\partial X_{f b}} & \\
\frac{\partial F_{S_{m b}}}{\partial X_{m b-f b}} & \frac{\partial F_{S_{f b}}}{\partial X_{m b-f b}} &
\end{array}\right]
$$

where

$$
\frac{\partial F_{S_{m b}}}{\partial X_{m b}}, \frac{\partial F_{S_{t t}}}{\partial X_{t t}}, \frac{\partial F_{S_{f b}}}{\partial X_{f b}}: \text { structural Jacobi matrices }
$$

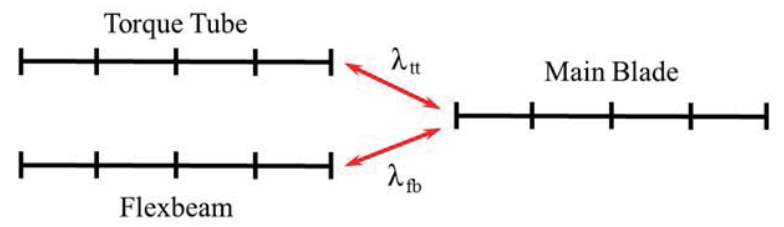

Fig. 2. Lagrange multipliers for multi-body modeling

$$
\begin{gathered}
\frac{\partial F_{S_{m b-t}}}{\partial X_{m b}}, \frac{\partial F_{S_{m b-t}}}{\partial X_{t t}}, \frac{\partial F_{S_{m b-f b}}}{\partial X_{m b}}, \frac{\partial F_{S_{m b-f b}}}{\partial X_{f b}}: \begin{array}{l}
\text { Jacobi matrices of the } \\
\text { constraint operators }
\end{array} \\
\frac{\partial F_{S_{m b}}}{\partial X_{m b-t t}}, \frac{\partial F_{S_{t t}}}{\partial X_{m b-t t}}, \frac{\partial F_{S_{m b}}}{\partial X_{m b-f b}}, \frac{\partial F_{S_{f b}}}{\partial X_{m b-f b}} \begin{array}{l}
\begin{array}{l}
\text { Jacobi matrices } \\
\text { of the constraint } \\
\text { variables }
\end{array}
\end{array}
\end{gathered}
$$

Equation (9) is divided into three parts. The structural Jacobi matrices are derivatives of the structural operators with respect to its unknowns. Each structural Jacobi matrix satisfies the boundary condition for each beam element. Jacobi matrices of the constraint operators and the constraint variables enforce the kinematic constraint at the clevis location. Jacobi matrices of the constraint operators are partial derivatives of the kinematic constraint equation at the clevis location. Jacobi matrices of the constraint variables are the partial derivatives of the structural operators with respect to the constraint variables at the clevis location. Thus, the structural constraints and boundary conditions were satisfied with the complete Jacobi matrix. In order to conduct time integration, the second-order Euler backward method with previous time steps was used and the NewtonRaphson iterative method was simultaneously used to solve the resulting nonlinear equation.

\subsection{Arbitrary location of the snubber}

Chun, et al. [14] modeled an elastomeric snubber as a combination of a six-degree-of-freedom linear spring and a damper. The snubber energy quantity was added to the total energy. The variational formulations of the strain energy and virtual work were obtained as follows.

$$
\begin{aligned}
& \delta U=k_{x}\left(\delta u_{t t}-\delta u_{f b}\right)\left(u_{t t}-u_{f b}\right)+k_{y}\left(\delta v_{t t}-\delta v_{f b}\right)\left(v_{t t}-v_{f b}\right) \\
& +k_{z}\left(\delta w_{t t}-\delta w_{f b}\right)\left(w_{t t}-w_{f b}\right)+k_{\theta 1}\left(\delta \theta_{1 t t}-\delta \theta_{1 f b}\right)\left(\theta_{1 t t}-\theta_{1 f b}\right) \\
& +k_{\theta 2}\left(\delta \theta_{2 t t}-\delta \theta_{2 f b}\right)\left(\theta_{2 t t}-\theta_{2 f b}\right)+k_{\theta 3}\left(\delta \theta_{3 t t}-\delta \theta_{3 f b}\right)\left(\theta_{3 t t}-\theta_{3 f b}\right) \\
& \delta W=-\left[\begin{array}{l}
\delta u_{t t}-\delta u_{f b} \\
\delta v_{t t}-\delta v_{f b} \\
\delta w_{t t}-\delta w_{f b} \\
\delta \theta_{1 t t}-\delta \theta_{1 f b} \\
\delta \theta_{2 t t}-\delta \theta_{2 f b} \\
\delta \theta_{3 t t}-\delta \theta_{3 f b}
\end{array}\right]\left[\begin{array}{cccccc}
c_{x} & & & & & \\
& c_{y} & & & & \\
& & c_{z} & & & \\
& & & c_{\theta_{1}} & & \\
& & & & c_{\theta_{2}} & \\
& & & & & \\
& & & & & c_{\theta_{2}}
\end{array}\right]\left[\begin{array}{c}
\dot{u}_{t t}-\dot{u}_{f b} \\
\dot{v}_{t t}-\dot{v}_{f b} \\
\dot{w}_{t t}-\dot{w}_{f b} \\
\dot{\theta}_{1 t t}-\dot{\theta}_{1 f b} \\
\dot{\theta}_{2 t t}-\dot{\theta}_{2 f b} \\
\dot{\theta}_{3 t t}-\dot{\theta}_{3 f b}
\end{array}\right]
\end{aligned}
$$

These energy terms were added to the total energy equation, Eq. (4). Then the revised formulation for a bearingless rotor with an elastomeric snubber was obtained as follows.

$$
\Pi=\Pi_{m b}+\Pi_{t t}+\Pi_{f b}+\Pi_{\text {snubber }}+\lambda_{t t} C_{t t}+\lambda_{f b} C_{f b}
$$

However, the snubber representation attempted in Ref. 14 puts it next to the most inboard beam element. This 
suggests that only linear or rotational variables for the most inboard beam element were considered in the snubber energy equation. Thus, such an approach is not capable of predicting accurate structural deflection at the inboard end. In order to predict the precise structural deflection at that location, an improved model for an arbitrary snubber location is required. To locate the snubber at an arbitrary location, an additional element was introduced to the torque tube and the flexbeam. The linear or rotational variables in the additional element were incorporated in the snubber energy equation. Given that the snubber is located between the torque tube and the flexbeam, only the inboard beam element was considered, as shown in Fig. 3. It represents the difference between the previous and present structural modeling approach, including the snubber.

By the application of such an approach, the bending deflection of the flexbeam at the imaginary hinge location caused by the snubber can be obtained.

\subsection{Rotor pitch control system flexibility}

The schematic view of the rotor blade and its pitch control system is shown in Fig. 4. The pitch horn, pitch link, and the rotating swashplate were considered in this paper. The pitch horn and the rotating swashplate were modeled as rigid bodies with negligible mass. The pitch link was modeled as a combination of an elastic linear spring and a linear viscous damper. The additional terms in the virtual variation in the strain energy and virtual work expressions due to the elastic pitch link can be written as follows.

$$
\delta U_{p l}=k_{p l} E_{p l} \delta E_{p l} \quad \delta W_{p l}=-c_{p l} \dot{E}_{p l} \delta E_{p l}
$$

where $E_{p l}$ is the elongation of the pitch-link. It was assumed that the vertical motion of the swash-plate was prescribed through the control inputs. The displacement of the pitch link was then obtained according to the mechanical behavior of the control system. Then $E_{p l}$ can be written as

$$
E_{p l}=L_{p l \_n e w}-L_{p l \_o l d}
$$

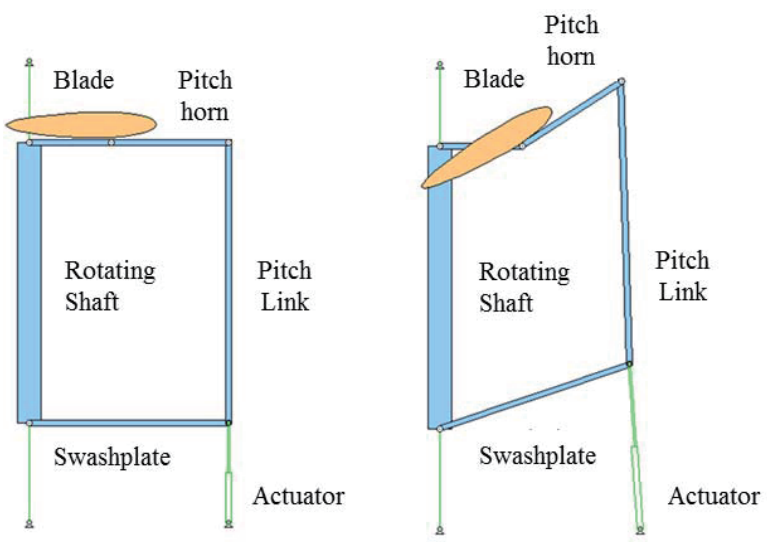

Fig. 4. Schematic view of the rotor pitch control system components

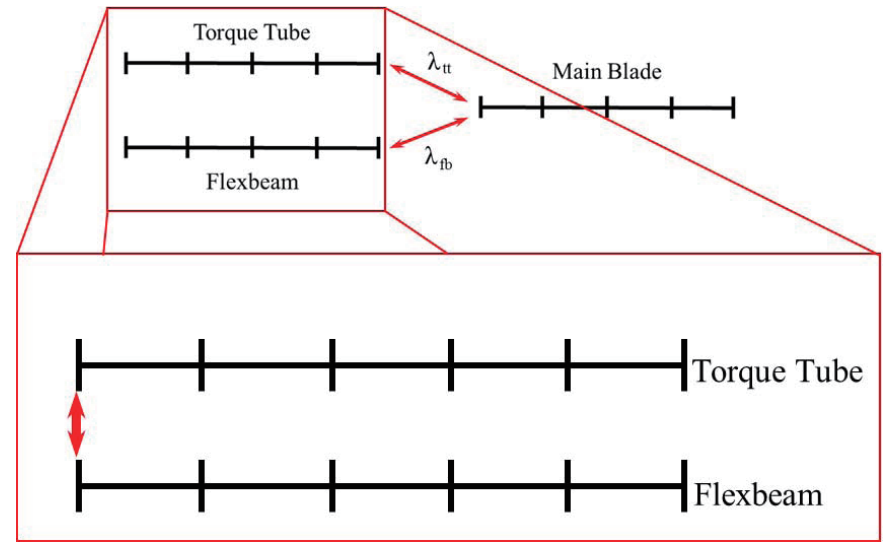

(a) Snubber model of Chun, et al [14]

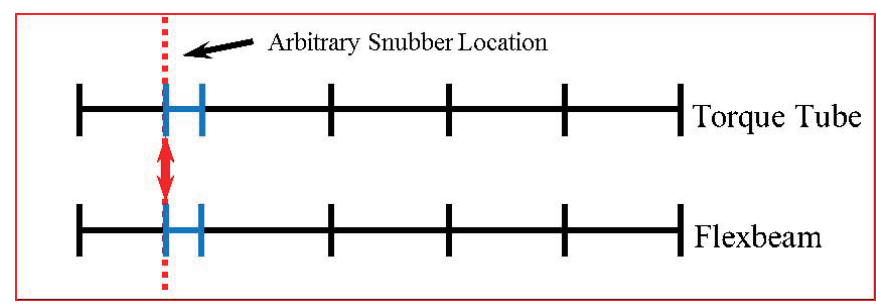

(b) Present snubber model

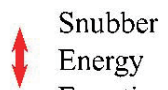

Equation

Additional

Element for Snubber

Fig. 3. Inboard beam element with an arbitrary snubber location 
By following this procedure, the blade root pitching moment and the load upon the pitch-link were determined in each time step from the additional energy and work terms.

\subsection{Finite-state unsteady aerodynamics}

In Ref. 14, two types of inflow model were combined with the structural analysis of a bearingless rotor. First, Glauert's uniform inflow model [18] was used for simple aerodynamic computation. The finite-state unsteady dynamic inflow aerodynamics [19], was also considered for aerodynamicstructural coupled analysis. Equations (16) and (17) represent the dynamic inflow value and the uniform inflow value, respectively.

$$
\begin{aligned}
& w(\bar{r}, \psi, \bar{t})=\sum_{r=0}^{\infty} \sum_{j=r+1, r+3, \ldots}^{\infty} \phi_{j}^{r}(\bar{r}) \times\left[\alpha_{j}^{r}(\bar{t}) \cos (r \psi)+\beta_{j}^{r}(\bar{t}) \sin (r \psi)\right] \\
& w=\frac{C_{T} / 2}{\sqrt{w^{2}+\mu^{2}}}
\end{aligned}
$$

Once the inflow values reached convergence, the airloads acting along each section would be estimated. However, in Ref. 14, to obtain aerodynamic forces using the dynamic inflow model, the inflow value, which was the summation of dynamic inflow and uniform inflow, was used. Consequently, an excessive inflow value was induced, and inaccurate airloads were obtained in Ref. 14.

In this paper, the aerodynamic inflow model was refined to consider the precise inflow value. Accurate inflow values were obtained for both the uniform inflow model and dynamic inflow model. For uniform inflow Eq. (17) was used, and Eq. (16) was used for dynamic inflow. Any superfluous terms were not added. Thus, the converged inflow values, without any unnecessary values, were used to obtain accurate airloads for each inflow model. Fig. 5 illustrates the improvement in this procedure. To find the sectional forces and moments, blade element theory and the two-dimensional aerodynamic table of the airfoil (C81 table) were employed.

\section{Numerical Results}

\subsection{Full scale bearingless rotor configuration}

In this paper, a full-scale bearingless rotor developed by the Korea Aerospace Research Institute (KARI) was used

Table 2. Characteristics of KARI bearingless rotor

\begin{tabular}{ccc}
\hline Characteristic & Symbol & Value \\
\hline Radius & $R$ & $5.82 \mathrm{~m}$ \\
Number of blades & $N_{b}$ & 4 \\
Mean Chord & $c$ & $0.27 \mathrm{~m}$ \\
Solidity & $\sigma$ & 0.0591 \\
Rotational speed & $\Omega$ & $36.55 \mathrm{rad} / \mathrm{s}$ \\
Clevis position & $R_{\text {clevis }}$ & $1.16 \mathrm{~m}$ \\
Snubber position & $R_{\text {snubber }}$ & $0.26 \mathrm{~m}$ \\
\hline
\end{tabular}

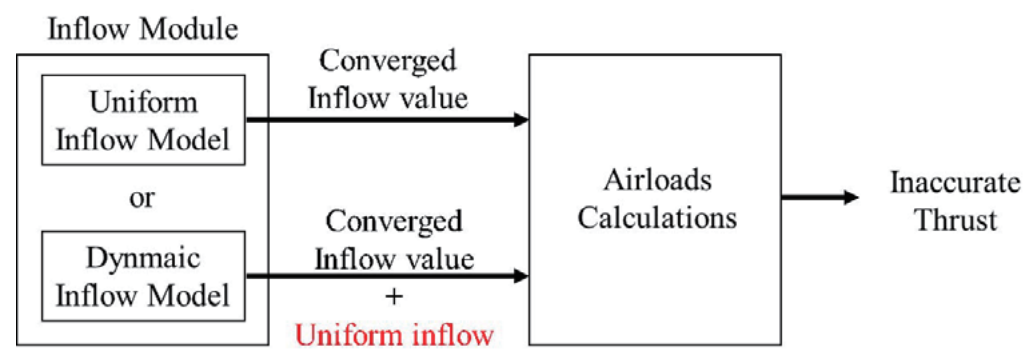

(a) Aerodynamic module of Ref. 14

Inflow Module

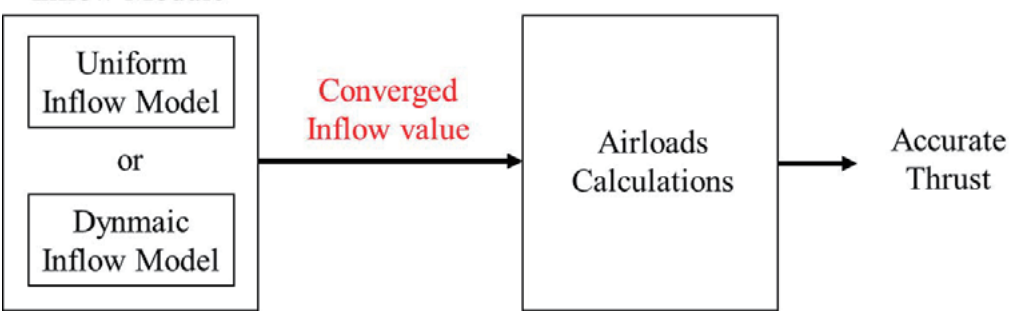

(b) Present aerodynamic module

Fig. 5. Improvement in the inflow computation 
to validate a presently extended aerodynamic-structural coupled model. This bearingelss rotor was designed and whirl-tested by KARI. The specific configurations of this bearingelss rotor are presented in Table 2 and Fig. 6 .

To validate the improvements of the present analysis, four different trim analyses and a collective sweep analysis were performed. For the hover analysis, both uniform inflow and dynamic inflow were combined in the present structural model. Also, to predict the behavior of the bearingless rotor under forward flight conditions, trim analyses were conducted regarding two different advance ratios. The results were compared with those predicted by the existing comprehensive helicopter analysis program, CAMRAD II. Finally, no trim load analysis with a constant collective sweep angle was performed and compared with the whirl tower experimental results. These analyses are summarized in Table 3.

\subsection{Frequency prediction}

Frequency prediction was conducted to investigate the dynamic characteristics of the bearingless rotor blade.

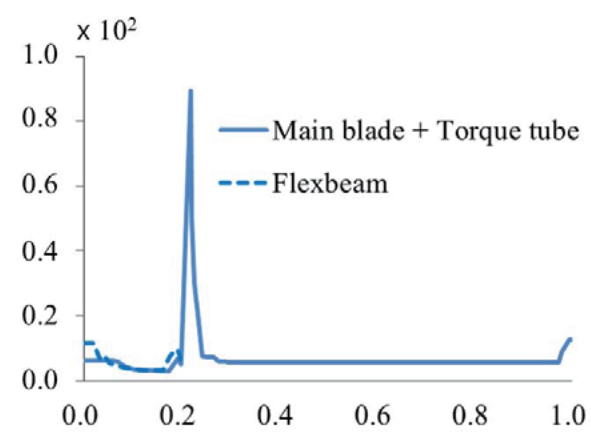

(a) Sectional Mass $[\mathrm{kg} / \mathrm{m}]$
Comparison result of natural frequencies, which were predicted by both the present analysis and CAMRAD II at the nominal rotational speed, is shown in Table 4 . The average difference of natural frequency between the present analysis and the CAMRAD II was less than $4 \%$. Thus, the validity of the present analysis was ascertained.

\subsection{Trim analysis results}

The trim analysis was performed for Cases 1 to 5 . Case 6 was a no-trim analysis in order to compare the measurements. This measurement provided only the flap moment result. Thus, the trim angle and aerodynamic results in Case 6 were not obtained. The results of trim angle for the various cases are presented in Fig. 7. They show good agreement with the values predicted by CAMRAD II. Also, aerodynamic results are shown in Fig. 8.

\subsection{Blade deflection}

The snubber included in the bearingless rotor was expected to exhibit distinctive movements. The role of the

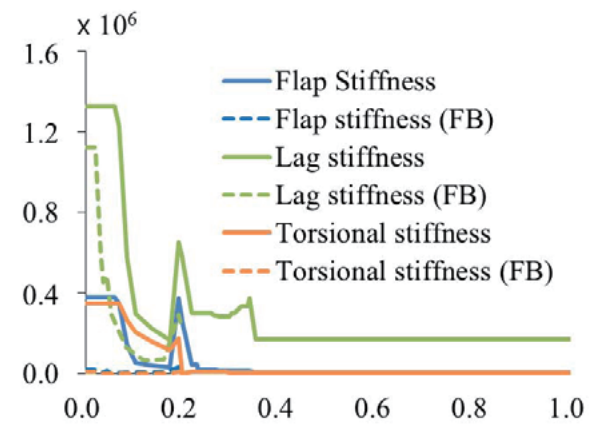

(b) Sectional Stiffness $\left[\mathrm{N}-\mathrm{m}^{2}\right]$

Fig. 6. Sectional properties of KARI bearingless rotor

Table 3. Computational cases for KARI bearingless rotor

\begin{tabular}{|c|c|c|c|c|c|c|}
\hline & Case 1 & Case 2 & Case 3 & Case 4 & Case 5 & Case 6 \\
\hline Trim/Non-trim & Trim & Trim & Trim & Trim & Trim & Non-Trim \\
\hline Trim target & & $\mathrm{C}_{\mathrm{T}} / \sigma=0.08$ & $\mathrm{Mx} / \sigma=0.0$ & $\mathrm{My} / \sigma=0.00$ & & N/A \\
\hline Inflow type & $\begin{array}{l}\text { Uniform } \\
\text { inflow }\end{array}$ & $\begin{array}{c}\text { Dynamic } \\
\text { inflow }\end{array}$ & $\begin{array}{c}\text { Dynamic } \\
\text { inflow }\end{array}$ & $\begin{array}{l}\text { Dynamic } \\
\text { inflow }\end{array}$ & $\begin{array}{c}\text { Dynamic } \\
\text { inflow }\end{array}$ & $\begin{array}{c}\text { Dynamic } \\
\text { inflow }\end{array}$ \\
\hline Advance ratio & 0.0 & 0.0 & 0.1 & 0.2 & 0.3 & 0.0 \\
\hline Collective input & \multicolumn{5}{|c|}{ N/A } & $1^{\circ}, 3^{\circ}, 5^{\circ}$ \\
\hline
\end{tabular}

Table 4. Natural frequencies at the nominal speed for KARI bearingless rotor

\begin{tabular}{cccccc}
\hline \multirow{2}{*}{$\omega / \Omega_{\text {ref }}$} & \multicolumn{2}{c}{ Flap } & \multicolumn{2}{c}{ Lag } & Torsion \\
\cline { 2 - 6 } & 1st & 2nd & 1st & 2nd & 1st \\
\hline CAMRAD II & 1.035 & 2.619 & 0.680 & 4.919 & 4.007 \\
Present & 1.109 & 2.718 & 0.679 & 4.925 & 4.245 \\
Difference & $6.7 \%$ & $3.6 \%$ & $0.1 \%$ & $0.3 \%$ & $5.6 \%$ \\
\hline
\end{tabular}


snubber is to separate the point of the flap bending and the lag bending. The snubber was designed so that the flap bending may occur between the hub and snubber. Significant lag bending occurs outboard of the snubber location, as shown in Fig. 9. Fig. 10 shows magnified plots focused on the hub. It reveals that our predictions were accurate and show good agreement with CAMRAD II, within a discrepancy 5\%. Thus, the structural deflection considering an arbitrary snubber location was validated.

\subsection{Internal loads analysis}

Figures 11-15 illustrate the comparison for the internal loads distribution in a trimmed situation, predicted at the azimuthal location of $270^{\circ}$ against those predicted by CAMRAD II. In all the cases considered the trend was similar to those predicted by CAMRAD II. However, the discrepancies between the present prediction and CAMRAD II were observed to be different for the cases considered.

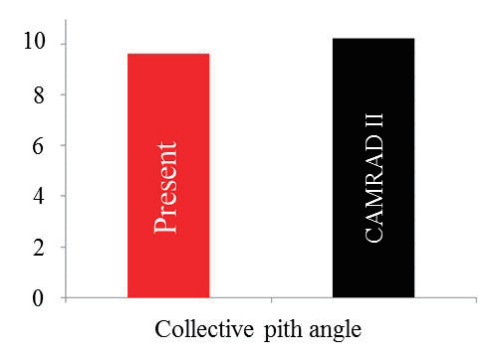

(a) Case $1\left[^{\circ}\right]$

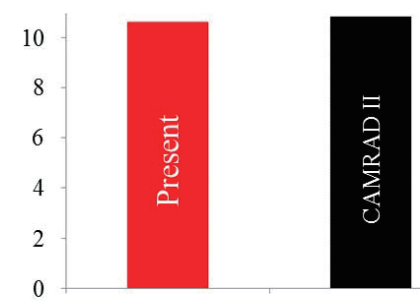

Collective pith angle

(b) Case $2\left[^{\circ}\right]$

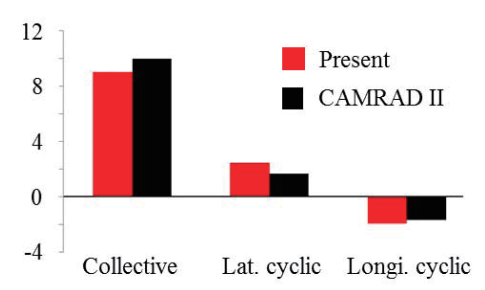

(c) Case $3\left[^{\circ}\right]$

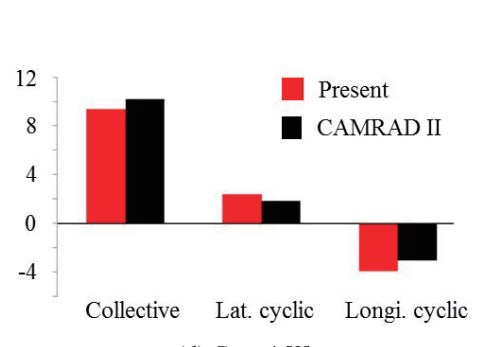

(d) Case $4\left[^{\circ}\right]$

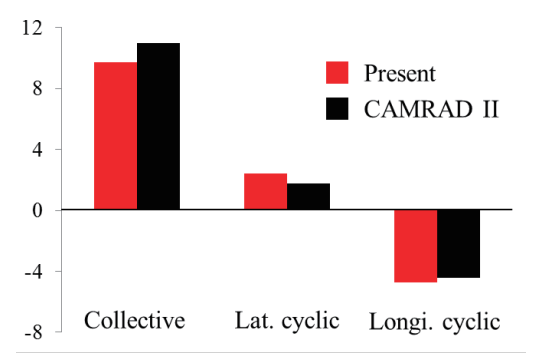

(e) Case $5\left[^{\circ}\right]$

Fig. 7. Trim control angle prediction results

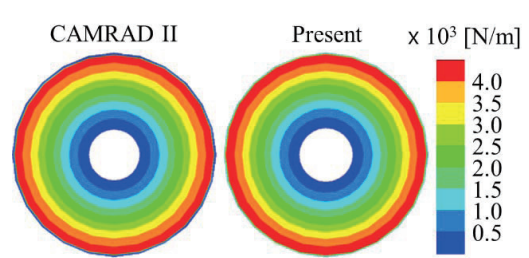

(a) Case 1

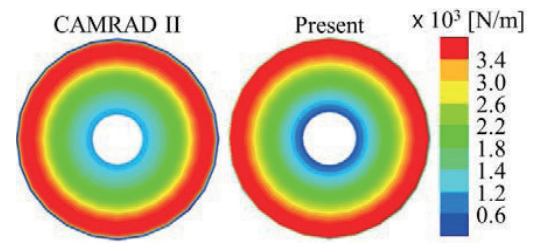

(b) Case 2

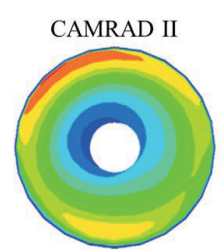

(c) Case 3

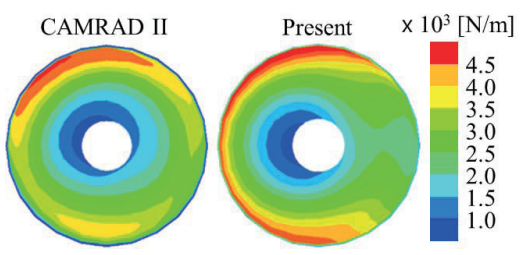

(d) Case 4

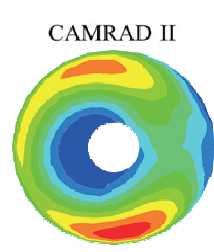

(e) Case 5

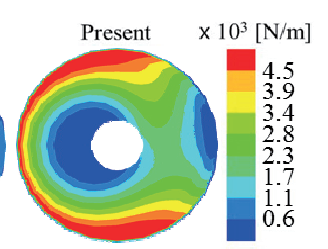

Fig. 8. Distribution of the sectional lift

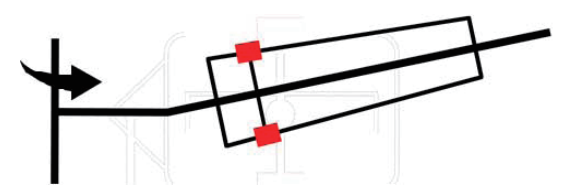

(a) Flap motion

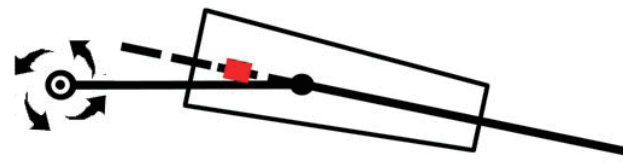

(b) Lag motion

Fig. 9. Schematic of the bending motions caused by the snubber 
First, in the hover condition with the uniform inflow model, a difference of approximately $12 \%$ was found. Significant discrepancies in the axial force and torsional moment at the inboard section can also be seen in Fig. 11. Thus, a sophisticated aerodynamic representation is required instead of the uniform inflow model. For the hover condition predicted by the dynamic inflow model, a $7 \%$ difference was found. In the forward flight trim condition, the advance ratios, $0.1,0.2$ and 0.3 , show approximately $8 \%, 10 \%$ and $7 \%$ discrepancies, respectively. This implies that forward flight trim analysis at a high advance ratio requires a more sophisticated analysis.

However, notable discrepancies still exist for the inboard section despite the combined dynamic inflow model. The present discrepancies were caused by differences in the aerodynamic analysis. In CAMRAD II, aerodynamic forces were obtained with exact structural deflections but the present approach considered only second order structural deformation. Also, only airloads acting on the main blade section were considered. Therefore, in order to predict the behaviors of the inboard blade section, airloads on the torque tube have to be included in the aerodynamic analysis. The aerodynamic forces obtained by the exact structural deflection, and airloads on the inboard section will require a more accurate prediction at the inboard section.

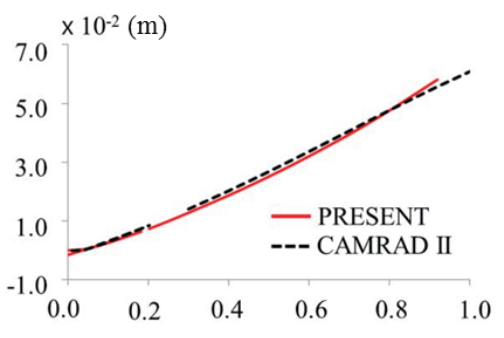

(a) Case 1. Flap deflection [m]

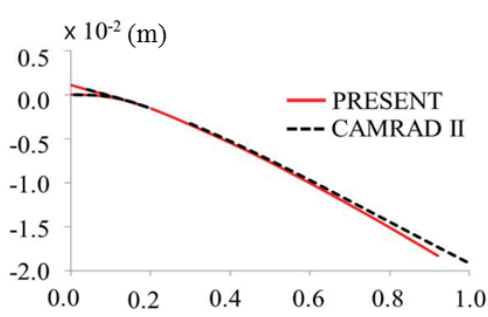

(d) Case 2. Lead-lag deflection [m]

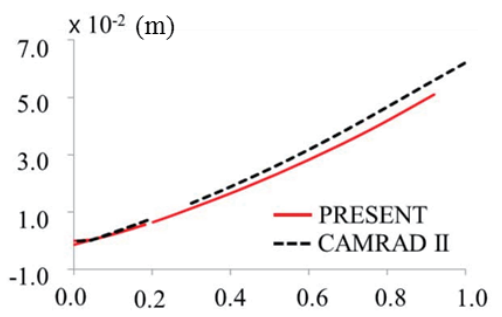

(g) Case 4. Flap deflection [m]

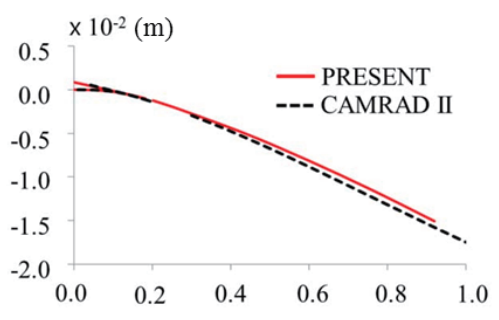

(b) Case 1. Lead-lag deflection [m]

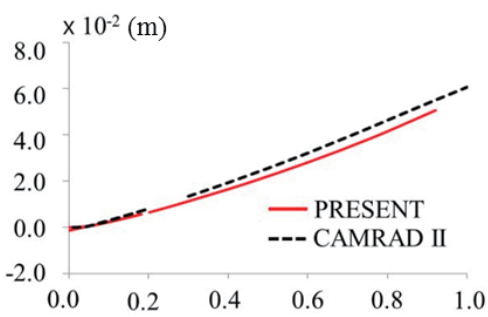

(e) Case 3. Flap deflection [m]

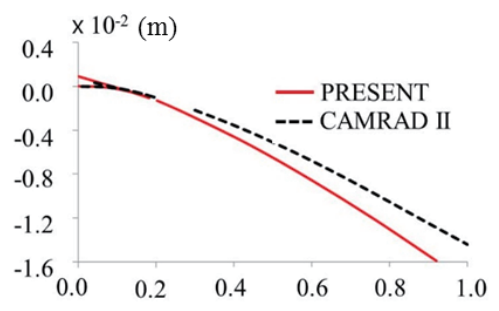

(h) Case 4. Lead-lag deflection [m]

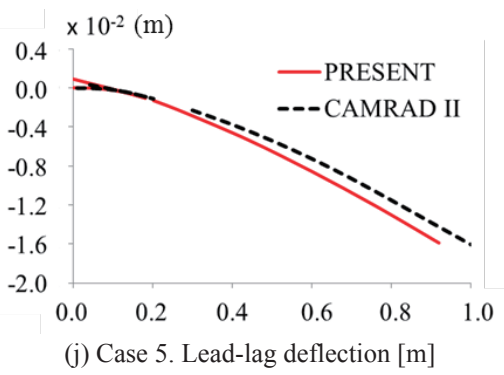

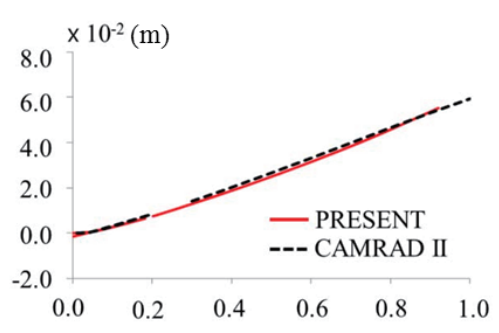

(c) Case 2. Flap deflection [m]

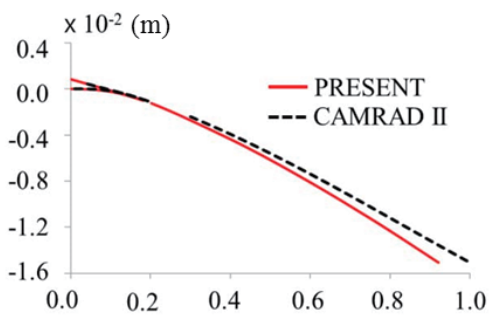

(f) Case 3. Lead-lag deflection [m]

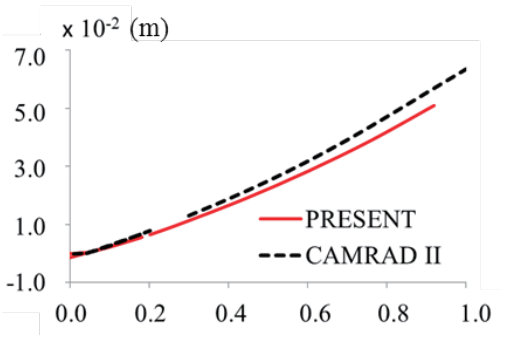

(i) Case 5. Flap deflection $[\mathrm{m}]$

Fig. 10. Blade deflection in the trim analysis at the azimuthal location $270^{\circ}$ 
Figure 16 shows the flap moment distributions from the present prediction and CAMRAD II as well as the measurement for Case 6 . In Case 6 with a $5^{\circ}$ collective pitch angle, it shows a similar trend to the measurements while the averaged discrepancy was smaller than $\mathbf{8 \%}$. However, there were discrepancies in the $1^{\circ}$ collective pitch angle case. For the inboard section, predictions from the present analysis and CAMRAD II were quite different. The average difference in the main blade flap moment between the present and the measured value was less than $4 \%$. Thus, for the inboard section, especially for a low collective pitch angle, we need a further sophisticated aerodynamic-structural analysis.

The improved aerodynamic-structural analysis was also validated. The present structural model including

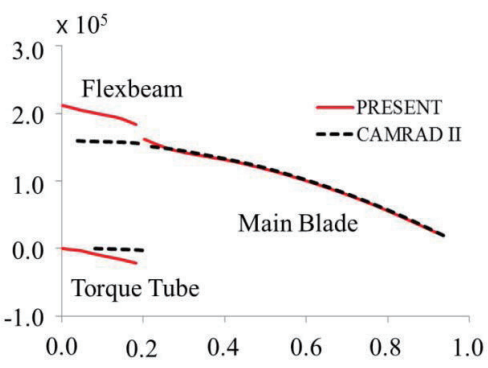

(a) Axial force $[\mathrm{N}]$

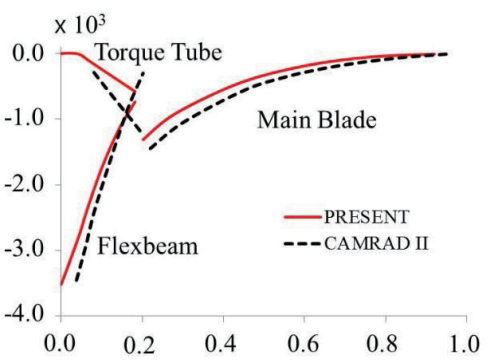

(d) Flap moment $[\mathrm{N}-\mathrm{m}]$

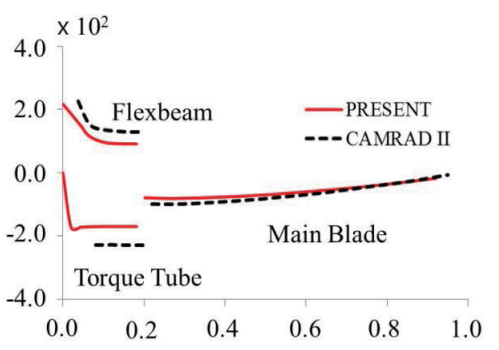

(b) Torsional moment $[\mathrm{N}-\mathrm{m}]$

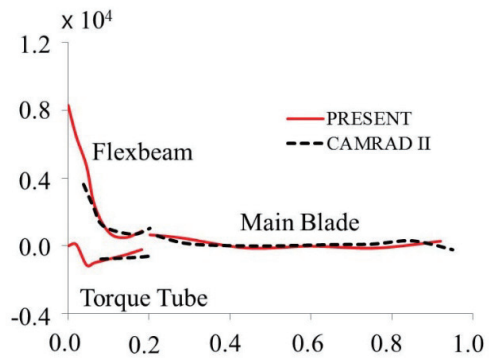

(e) Normal force $[\mathrm{N}]$

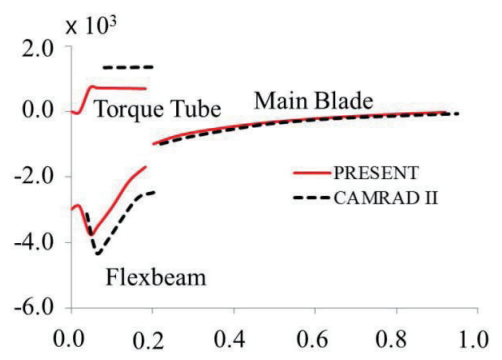

(c) Chordwise force $[\mathrm{N}]$

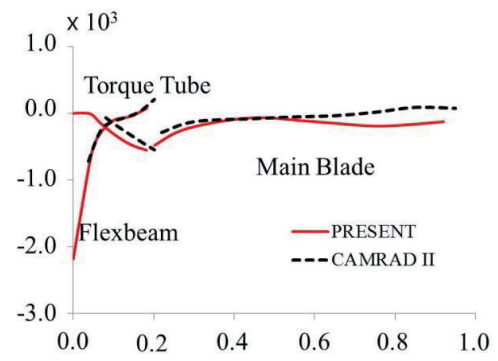

(f) Lag moment $[\mathrm{N}-\mathrm{m}]$

Fig. 11. Internal loads distribution predicted (Case 1, $\mu=0.0$ ).

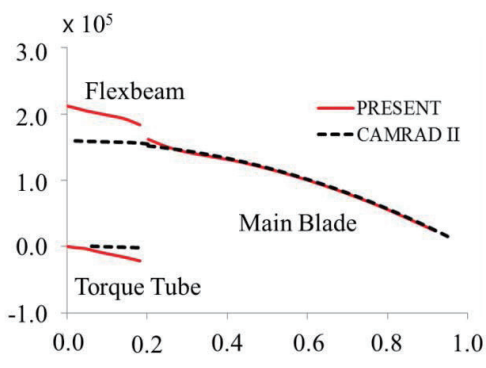

(a) Axial force $[\mathrm{N}]$

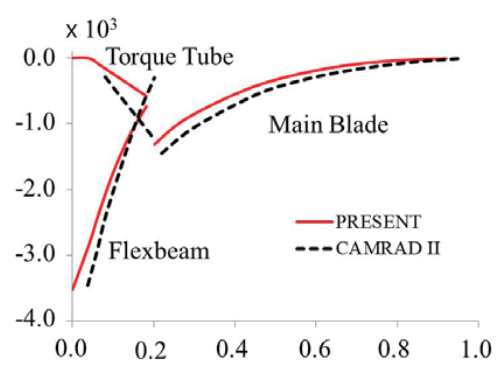

(d) Flap moment $[\mathrm{N}-\mathrm{m}]$

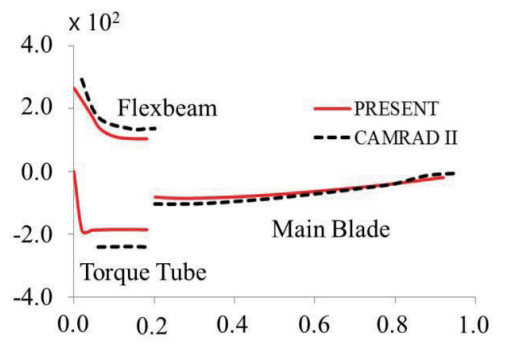

(b) Torsional moment $[\mathrm{N}-\mathrm{m}]$

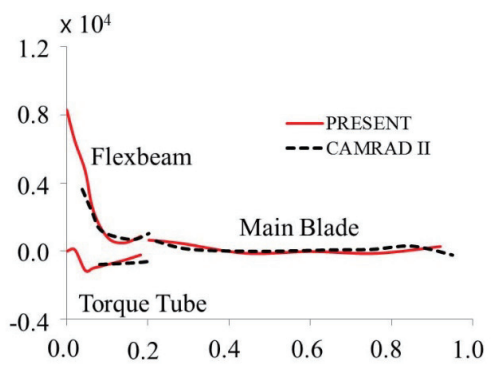

(e) Normal force $[\mathrm{N}]$

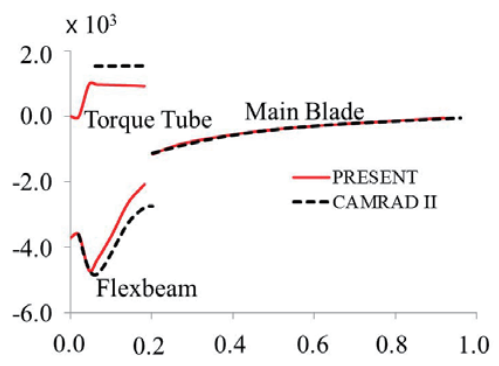

(c) Chordwise force $[\mathrm{N}]$

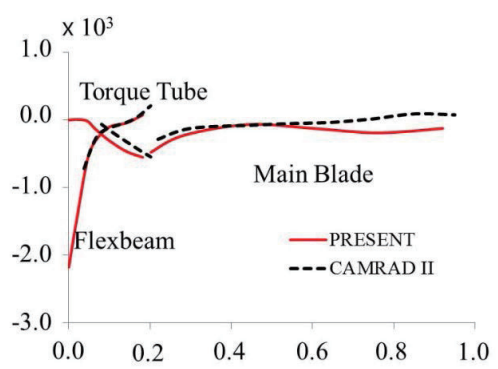

(f) Lag moment $[\mathrm{N}-\mathrm{m}]$

Fig. 12. Internal loads distribution predicted (Case $2, \mu=0.0$ ). 
the kinematic constraints, boundary conditions, arbitrary snubber location, and the pitch control system. The coupled analysis using the refined aerodynamic model, exhibited similar trends for the internal loads and structural deflection compared with those made by CAMRAD II and the measurements. Also, distributions of the internal loads were examined at the clevis location for both the present analysis and CAMRAD II. At the clevis location, the sum of internal loads between the flexbeam and torque tube was the same as that of the main blade. The continuity of the internal loads was confirmed by the present analysis.

Although the aerodynamic-structural analytic procedure was improved by considering the arbitrary snubber location and pitch control system, a few aspects were not

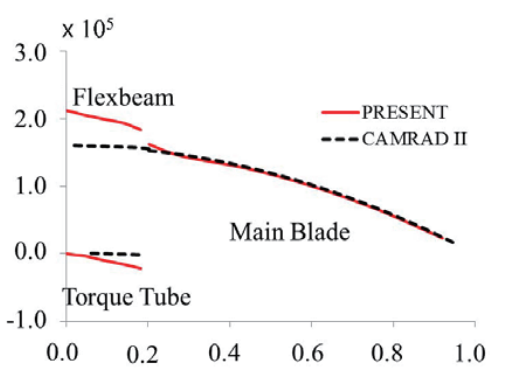

(a) Axial force [N]

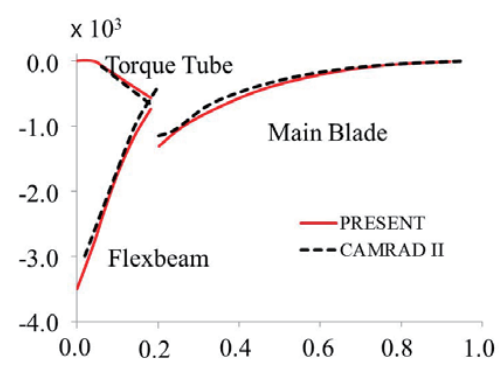

(d) Flap moment [N-m]

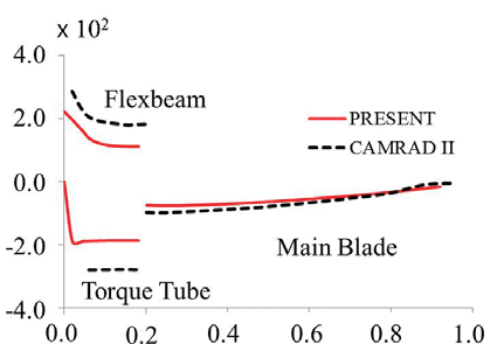

(b) Torsional moment $[\mathrm{N}-\mathrm{m}]$

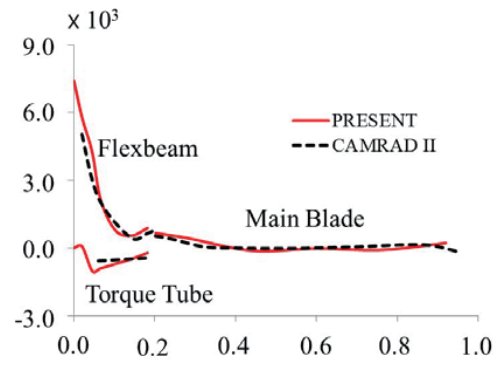

(e) Normal force $[\mathrm{N}]$

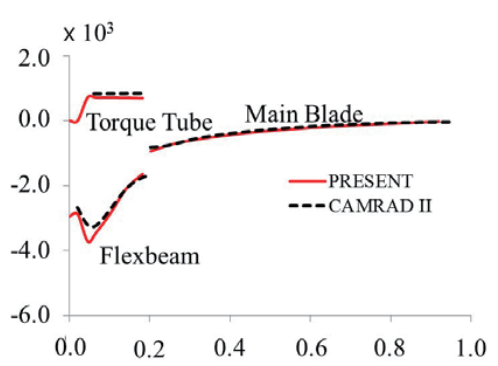

(c) Chordwise force [N]

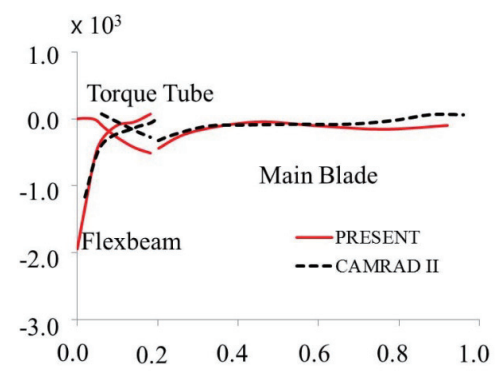

(f) Lag moment [N-m]

Fig. 13. Internal loads distribution predicted (Case 3, $\mu=0.1$ ).

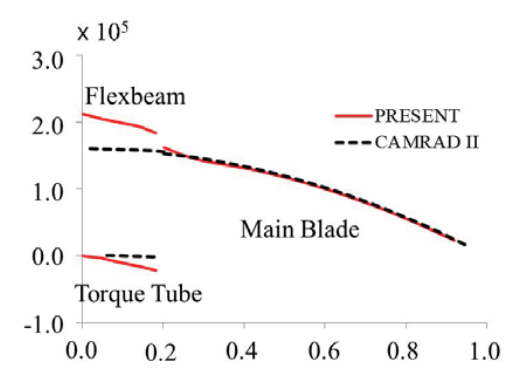

(a) Axial force [N]

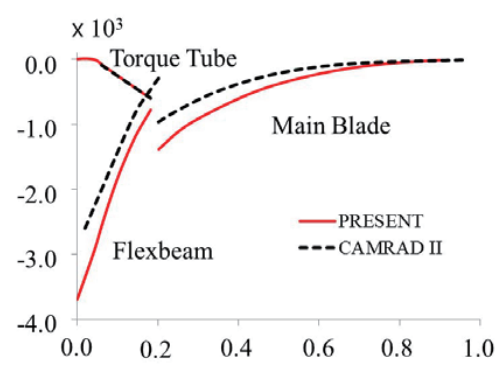

(d) Flap moment $[\mathrm{N}-\mathrm{m}]$

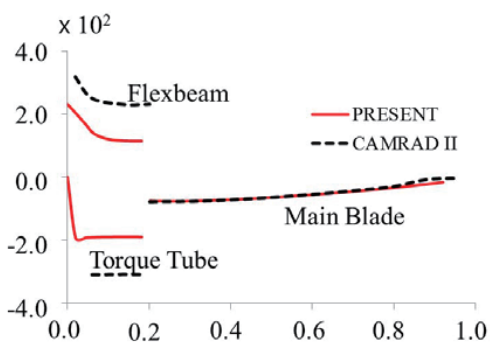

(b) Torsional moment $[\mathrm{N}-\mathrm{m}]$

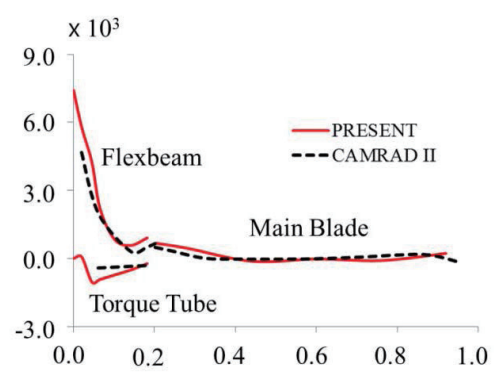

(e) Normal force $[\mathrm{N}]$

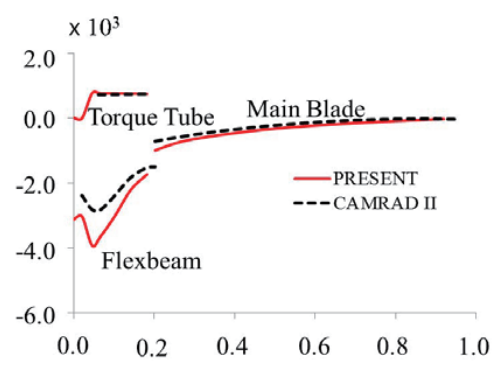

(c) Chordwise force [N]

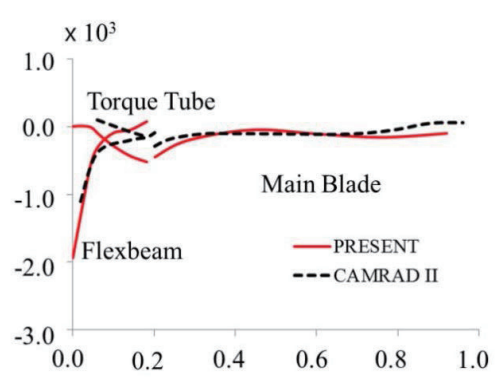

(f) Lag moment $[\mathrm{N}-\mathrm{m}]$

Fig. 14. Internal loads distribution predicted (Case $4, \mu=0.2$ ). 
implemented. Lead-lag dampers were not included in the present structural model. Lead-lag dampers are present in most rotor systems to provide the desired level of damping for all flight conditions. For a more precise prediction, lead-lag dampers will be added to the present structural model.

Furthermore, in the non-trim analysis, only the flap moment was compared with the present analysis. Other important quantities, such as internal forces, torsional moment, lag moment, and structural deflection have to be compared to validate the present, improved aerodynamicstructural analysis. Also, more accurate aerodynamic loads from the computational fluid dynamics and experiment were required to perform accurate, aerodynamicstructural coupled analysis. In this paper, relatively simple aerodynamics computations according to blade element theory were used.

\section{Conclusions}

An improved aerodynamic-structural analysis for a bearingless rotor was developed in this paper. A precise structural model considering kinematic constraints and boundary conditions was implemented. In our model the snubber can be located at an arbitrary position and the pitch control system are included. Our improved structural model was combined with the various inflow aerodynamic models. Numerical results for the various flight conditions and inflow models showed that the present analysis predicted the behavior of a bearingless rotor more accurately than in previous work. Numerical results were verified by comparison against the predictions made by CAMRAD II and experimental measurement.

Trim analysis was performed for the KARI bearingless rotor. The results showed that the trimmed angles were over

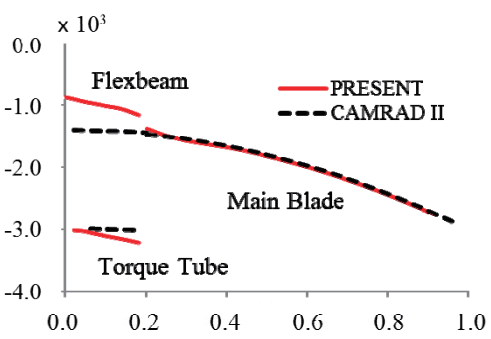

(a) Axial force $[\mathrm{N}]$

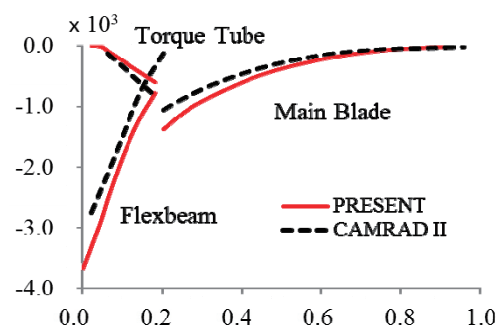

(d) Flap moment $[\mathrm{N}-\mathrm{m}]$

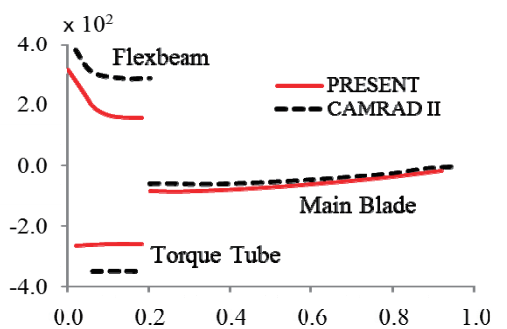

(b) Torsional moment $[\mathrm{N}-\mathrm{m}]$

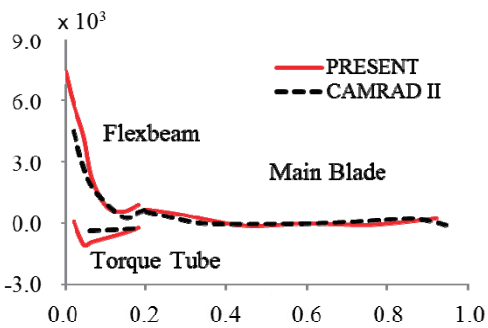

(e) Normal force $[\mathrm{N}]$

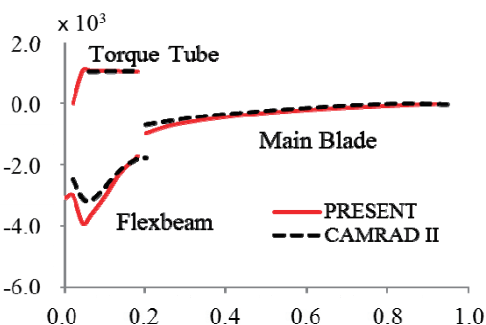

(c) Chordwise force $[\mathrm{N}]$

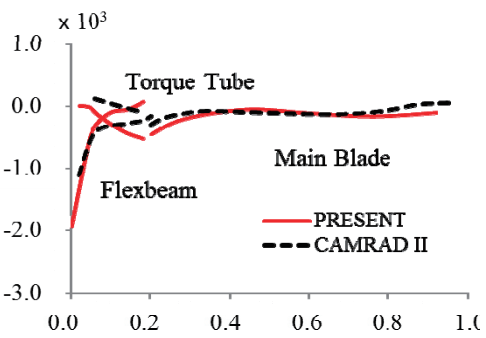

(f) Lag moment $[\mathrm{N}-\mathrm{m}]$

Fig. 15. Internal loads distribution predicted (Case $5, \mu=0.3$ ).

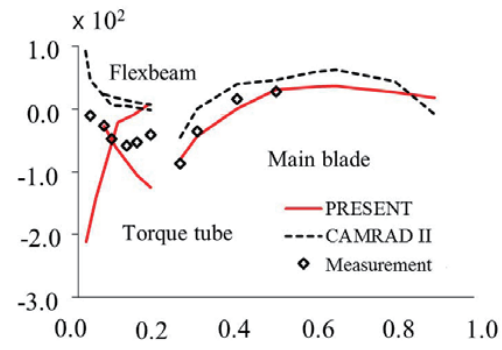

(a) Collective pitch : $1^{\circ}$

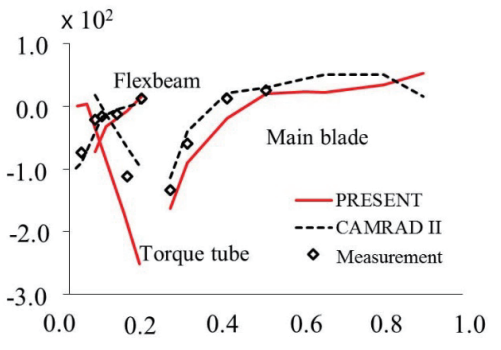

(b) Collective pitch : $3^{\circ}$

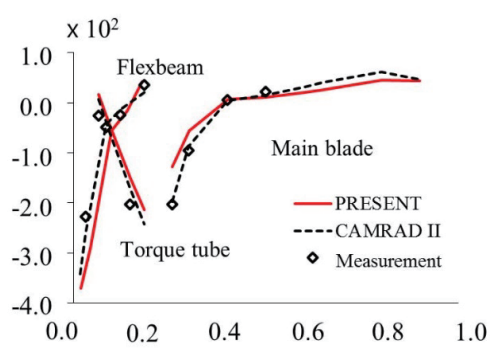

(c) Collective pitch : $5^{\circ}$

Fig. 16. Flap moment distribution predicted (Case 6). 
$90 \%$ in term of similarity and the aerodynamic quantity distributions were similar to those predicted by CAMRAD II. The present model's predictions for blade deformation caused by the snubber under the same trim condition showed excellent agreement with a less than $5 \%$ discrepancy with those made by CAMRAD II. The results for internal load distribution had a $10 \%$ difference compared to those made by CAMRAD II. Finally, in order to compare with the whirl tower experimental values, aerodynamic-structural coupled analysis was performed under no trim collective sweep conditions. The flap moment had a less than $10 \%$ difference compared to measurement. However, the values predicted for the inboard section of the $1^{\circ}$ collective pitch case show significant differences.

\section{Acknowledgement}

This work was supported by National Research Foundation of Korea (NRF) Grant (0420-20110108) and Korea Ministry of Land, Transport and Maritime Affairs as Haneul Project.

\section{References}

[1] Hodges, D. H., "An Aeromechanical Stability Analysis for Bearingless Rotor Helicopters," Journal of the American Helicopter Society, Vol. 24, No. 1, 1979, pp. 2-9.

[2] Bousman, W. G., An Experimental Investigation of Hingeless Helicopter Rotor-body Stability in Hover, NASA TM 78489, 1978.

[3] Chen, C., Staley, J.A., Miao, W. and Harris, F.D., Aeroelastic Stability Test Results for a 115.86 Froude Scale Model of a Bearingless Main Rotor System on the BO-I05 Helicopter, U.S. Army AMRDL Report for Contract DAA J0276-C-W26, June 1977.

[4] Lim, I. G. and Lee, I. "Aeroelastic Analysis of Bearingless Rotors using Large Deflection Beam Theory," AIAA Journal, Vol. 45, 2007, pp. 599-606.

[5] Staruk, W., Chopra, I. and Datta, A. “Three-Dimensional CAD-Based Structural Modeling for Next Generation Rotor Dynamic Analysis," American Helicopter Society 70th Annual Forum, Montréal, Québec, Canada, May 20-22, 2014.

[6] Ananthan, S. and Baeder, J. D. "Prediction and Validation of Load on Bearingless Rotors using a Coupled CFD-CSD Methodology," American Helicopter Society 64th Annual Forum, Montreal, Canada, April 29-May 1, 2008.

[7] Nguyen, K., Lauzon, D. and Anand, V., "Computation of Loads on the McDonnell Douglas Advanced Bearingless Rotor," American Helicopter Society 50th Annual Forum, Washington D. C., May 11-13, 1994.

[8] Nguyen, K., McNulty, M., Anand, V. and Lauzon, D., Aeroelastic Stability of the McDonnell Douglas Advanced Bearingless Rotor in the 40- $\times$ 80-Foot Wind Tunnel, NASA TM-108831, 1994.

[9] Johnson, W., "Technology Drivers in the Development of CAMRAD II," Proceedings of the AHS Aeromechanics Specialist Conference, AHS International, Alexandria, VA, 1994, pp. 3.1-3.14.

[10] Johnson, W., Comprehensive Analytical Model of Rotorcraft Aerodynamics and Dynamics, Vols III, Johnson Aeronautics, VIII Palo Alto, CA Sep, 2000, pp. 120-121.

[11] Johnson, W., Personal communication, Johnson Aeronautics, Palo Alto, CA, USA, 12th June 2014.

[12] Sotoudeh, Z. and Hodges, D. H., "Structural Dynamics Analysis of Rotating Blades Using Fully Intrinsic Equations, Part I: Formulation and Verification of Single-Load-Path Configurations," Journal of the American Helicopter Society, Vol. 58, No. 3, 2013, pp.1-9.

[13] Sotoudeh, Z. and Hodges, D. H., "Structural Dynamics Analysis of Rotating Blades Using Fully Intrinsic Equations, Part II: Dual-Load-Path Configurations," Journal of the American Helicopter Society, Vol. 58, No. 3, 2013, pp.1-9.

[14] Chun, T. Y., Ryu, H. Y., Cho, H. S., Shin, S.J., Kee, Y. J. and Kim, D. J., "Structural Analysis of a Bearingless Rotor using an Improved Flexible Multi-body Model," Journal of Aircraft, Vol. 50, No. 2, 2013, pp. 539-550.

[15] Kim, D. G., Kim, M. H., Yun, C. Y., Kim, T. J. and Kim, S. H., "A Preliminary Design of the Bearingless Rotor Hub System of Helicopter," KSAS 2011 Spring Conference, KyungJu, Korea, April 13-15, 2011.

[16] Gerald Kuntze-Fechner, G., Bauer, M. and Ortner, M., "Airfoil blade of a bearingless rotor of a helicopter," United States Patent, 20130280076 Al, March, 2013.

[17] Hodges, D. H., "A Mixed Variational Formulation Based on Exact Intrinsic Equations for Dynamics of Moving Beams," International Journal of Solids and Structures, Vol. 26, No. 11, 1990, pp. 1253-1273.

[18] Peters, D. A. and He, C. J., "Finite State Induced Flow Models Part II: Three-Dimensional Rotor Disk," Journal of Aircraft, Vol. 32, No. 2, March-April, 1995.

[19] Bradley, R., Black, C.G. and Murray-Smith, D.J. "Glauert augmentation of rotor inflow dynamics," 15th European Rotorcraft Forum, Amsterdam, The Netherlands, September 12-15, 1989. 